\title{
Healthy Eating: Improve Nutrition with SNAP ${ }^{1}$
}

\author{
Linda B. Bobroff ${ }^{2}$
}

SNAP (the Supplemental Nutrition Assistance Program, formerly called Food Stamps) is one of several nutrition programs that help people meet their dietary needs. Millions of older adults who are eligible for SNAP benefits do not receive them. If you think you may be eligible, please call the Elder Help Line (1-800963-5337) today and ask for more information and help with applying. You can also find more information about SNAP at this website: http:// www.fns.usda.gov/snap.

\section{What is SNAP?}

SNAP is a nutrition program that helps people with limited resources buy healthy foods. The US Department of Agriculture (USDA) provides this program to eligible persons of all ages. SNAP provides an easy-to-use Benefit Security ${ }^{\oplus}$ Card, commonly called an EBT (Electronic Benefit Transfer) card. The EBT card is secure and is widely accepted in stores and at many farmers' markets.

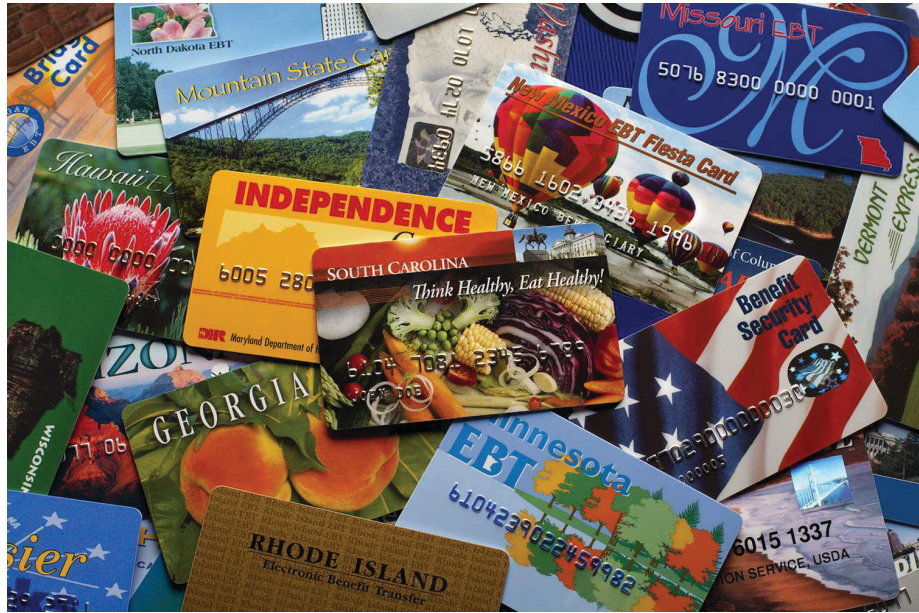

Figure 1. Benefit Security ${ }^{\circledR}$ Card / EBT (Electronic Benefit Transfer) card.

Credits: http://snap.nal.usda.gov/ebt-cards-several-states

\section{Isn't this "welfare"?}

No! SNAP is a USDA nutrition program that helps people with limited resources have a healthy diet. Everyone deserves to have enough to eat and access to foods they enjoy.

\section{How much can I get?}

The average monthly SNAP benefit per person nationwide was $\$ 127$ in 2014. Having even

1. This document is FCS8837 (la versión en español de este documento es Alimentación Saludable: Mejore su nutrición con SNAP (FCS8837-Span)), one of a series of the Department of Family, Youth and Community Sciences, UF/IFAS Extension. Original publication date January 2007. Revised November 2016. Visit the EDIS website at http://edis.ifas.ufl.edu.

2. Linda B. Bobroff, PhD, RD, LD/N, professor, Department of Family, Youth and Community Sciences; UF/IFAS Extension, Gainesville, FL 32611. 
an extra few dollars each week for groceries can help. Figure 2 shows what approximately $\$ 25$ can buy (cost of food varies depending on where you live).

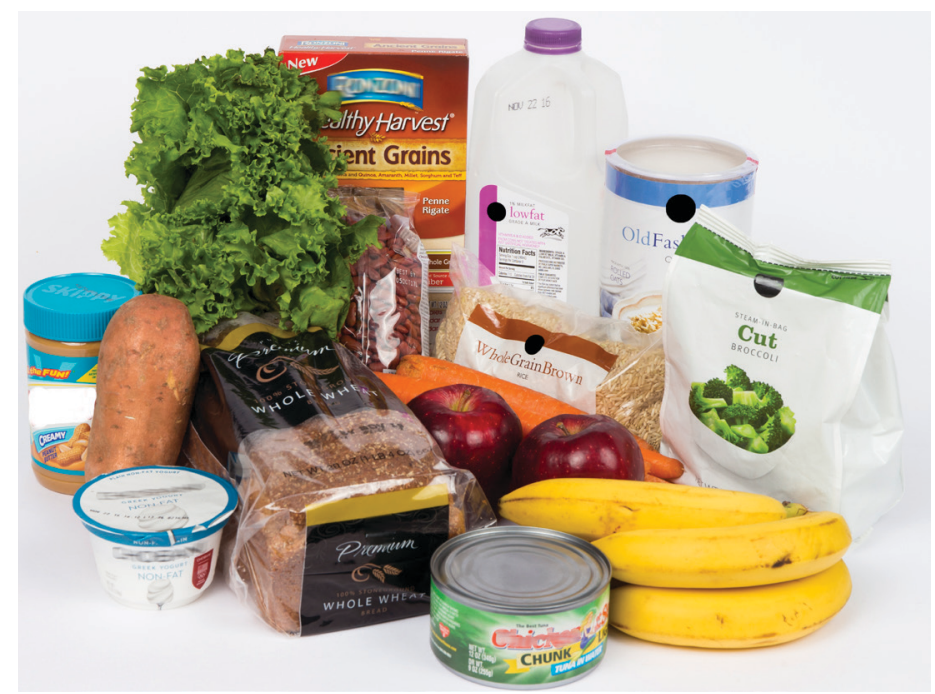

Figure 2. A little really can go a long way towards nutritious foods, including broccoli, tuna, peanut butter, bananas, apples, kidney beans, oats, whole-grain bread, carrots, brown rice, low-fat milk, whole-grain pasta, leaf lettuce, sweet potato, and yogurt-all ingredients for healthy eating!

Credits: UF/IFAS photo 